\title{
Long-term survival and late complications of intensity-modulated radiotherapy for recurrent nasopharyngeal carcinoma
}

\author{
Fangfang Kong ${ }^{1,2+}$, Junjun Zhou ${ }^{1,2,3+}$, Chengrun Du ${ }^{1,2}$, Xiayun He ${ }^{1,2}$, Lin Kong ${ }^{1,2,4}$, Chaosu Hu ${ }^{1,2}$ and
} Hongmei Ying ${ }^{1,2^{*}}$

\begin{abstract}
Background: To evaluate the effectiveness and toxicities of intensity-modulated radiotherapy (IMRT) for locally recurrent nasopharyngeal carcinoma (NPC).

Methods: One hundred and eighty-four previously irradiated NPC patients with recurrent disease and re-irradiated by IMRT between February 2005 to May 2013 had been reviewed. The disease was re-staged I in 33, II in 27, III in 70 and IV in 54 patients. Seventy-five percent of the patients received cisplatin-based chemotherapy.

Results: The median survival time was 33 months. The 3-year actuarial rates of local recurrence-free survival (LRFS), distant metastases-free survival (DMFS), and overall survival (OS) rates were 85.1, 91.1, and 46.0\%, respectively. About 53\% of the patients experienced Grade 3-4 late toxicities. Forty-four patients died of massive hemorrhage of the nasopharynx caused by radiation induced mucosal necrosis. Multivariate analysis indicated that chemotherapy and time interval between initial radiotherapy and re-irradiation were independent predictors for DMFS.

Conclusion: IMRT is an effective method for patients with locally recurrent NPC. Massive hemorrhage of the nasopharynx is the major sever late complication and also the leading cause of death. Early recurrence is negative factor for DMFS. Combination of chemotherapy can improve DMFS, but not for OS. Optimal salvage treatment strategies focusing on improvement of survival and minimization of late toxicities are warranted.
\end{abstract}

Keywords: Intensity-modulated radiotherapy, IMRT, Recurrent nasopharyngeal carcinoma, NPC, Re-irradiation, Survival, Late complication

\section{Background}

Recurrent nasopharyngeal carcinoma (NPC) occurred in 20-40\% for patients treated with traditional radiotherapy [1-3]. With the development of modern radiation technique, the local control has been definitely improved. However, recurrence inevitably happens in some patients, especially those with local-regionally advanced disease [4]. Salvage treatment for locally recurrent NPC remains a challenge for clinical oncologists. Various strategies, including surgery, brachytherapy, and stereotactic radiosurgery have

\footnotetext{
* Correspondence: yinghongmei2013@163.com

${ }^{\dagger}$ Fangfang Kong and Junjun Zhou contributed equally to this work.

${ }^{1}$ Department of Radiation Oncology, Fudan University Shanghai Cancer

Center, Shanghai, People's Republic of China

${ }^{2}$ Department of Oncology, Shanghai Medical College, Fudan University,

Shanghai, People's Republic of China

Full list of author information is available at the end of the article
}

been used in attempt to cure locally recurrent NPC in the past several decades [5-7]. However, their utility is usually limited by the extent of disease at recurrence. It is reported that $70-80 \%$ of the recurrent NPC were locally advanced [8-11]. For patients with infiltrative or extensive disease, definitive reirradiation is an important way of treatment. Since curative re-irradiation with conventional techniques is associated with a considerable risk of severe complications, including temporal lobe necrosis, trismus, mucosal ulcer and even fatal hemorrhage, the treatment planning is often difficult and poses a special challenge to radiation oncologists [12].

Intensity-modulated radiotherapy (IMRT) is an ideal radiation modality for NPC, due to its favorable balance between target coverage and the sparing of adjacent organs [13]. Published reports have shown that the use 
of IMRT for retreatment of locally recurrent NPC is clinically feasible and could produce acceptable disease control [8, 9, 12, 14, 15]. However, reports of long-term results with large samples were relatively rare. Herein, we reported our institutional experience of IMRT for recurrent NPC in 184 patients.

\section{Methods}

\section{Patients}

From February 2005 to May 2013, 184 patients with recurrent NPC treated by curative re-irradiation with IMRT in Fudan University Shanghai Cancer Center were enrolled in this study. All patients received complete assessment of history and physical examination, contrasted magnetic resonance imaging (MRI) of the nasopharynx and neck, chest computed tomography (CT) or radiography, abdominal ultrasound, endoscopy, complete blood test and emission-computed tomography (ECT) if necessary. All patients were re-staged according to the 2010 American Joint Committee on Cancer/Union for International Cancer Control staging system (AJCC/UICC 2010). This study was approved by the Institutional Review Boards of Fudan University Shanghai Cancer Center, China. Written informed consent was obtained from the patients before treatment. Due to the retrospective design of the study, the local ethic committee confirmed that informed consent was not necessary from participants.

\section{Treatment of recurrence}

\section{Intensity-modulated radiotherapy}

Patients received CT simulation at 3-5 mm thickness with custom head mask in the supine position. Contrasted MRI and CT image fusion was performed for target delineation. The gross tumor volume (GTV) included all recurrent tumors seen on diagnostic CT/MRI, endoscope and physical examinations. The clinical target volume (CTV) was defined as the GTV plus 5 to $10 \mathrm{~mm}$ margin to encompass any microscopic extension. The planning target volume (PTV) would encompass the CTV/GTV with a 3-5 $\mathrm{mm}$ margin in all directions.

Six-MV photons and simultaneous integrated boost (SIB) technique were used to treatment planning. The median dose was 66.7Gy (range, 42-77Gy). The fractional dose was $1.8-2.3$ Gy/day ( 5 days per week). Thirteen patients received brachytherapy boost.

\section{Chemotherapy}

Cisplatin-based neoadjuvant, concurrent, and/or adjuvant chemotherapy were administrated in patients with locally advanced disease or with a relatively short interval between the end of primary RT and tumor recurrence. Seventy-seven (41.8\%) patients received neoadjuvant chemotherapy, 46 (25\%) patients received IMRT alone. Nineteen patients received targeted agents (cetuximab or nimotuzumab). Details were shown in Table 1.

\section{Patient evaluation and follow up}

Tumor response and toxicities were assessed weekly during IMRT, every 3-6 months after treatment in the first 5 years, and yearly thereafter. Imaging examinations (MRI, CT and ultrasound) were performed 3 months after IMRT and then every 6-12 months. The final date of follow-up was October 12, 2016.

Treatment-related toxicities were graded according to National Cancer Institute Common Toxicity Criteria for Adverse Events (NCI-CTCAE) version 4.02.

\section{Statistical analysis}

The rates of local recurrence-free survival (LRFS), distant metastases-free survival (DMFS) and overall survival (OS) were estimated with the Kaplan-Meier method. The durations were calculated from the date of diagnosis of local recurrence to the date of each event occurred or the last follow-up. Log-rank tests and Cox proportional hazards model were used for univariate and multivariate analysis

Table 1 Treatment schedule for patients with locally recurrent NPC

\begin{tabular}{ll}
\hline Treatment schedule & No. (\%) \\
\hline Chemotherapy & $77(41.8)$ \\
Neo + RT & $23(12.5)$ \\
Neo + CCRT & $17(9.2)$ \\
Neo + RT + Adj & $10(5.4)$ \\
CCRT & $4(2.2)$ \\
CCRT+Adj & $2(1.1)$ \\
Neo + CCRT+Adj & $5(2.7)$ \\
RT + Adj & $46(25)$ \\
IMRT alone & $9(4.8)$ \\
Cetuximab & $10(5.4)$ \\
Nimotuzumab & \\
IMRT & \\
IMRT dose (Gy) & \\
Median (range) & $66.7(42-77)$ \\
Fractional dose(Gy) & \\
1.8 & $1(0.5)$ \\
2.0 & $125(67.9)$ \\
2.1 & $44(23.9)$ \\
2.2 & $6(3.3)$ \\
IMRT treatment duration (days) & $7(3.8)$ \\
Median (range) & \\
\hline Brachytherapy & $46(29-64)$ \\
\hline A & $13(7.1)$ \\
\hline
\end{tabular}

Abbreviations: NPC, nasopharyngeal carcinoma; Neo, neoadjuvant chemotherapy; $R T$, radiotherapy; CCRT, concurrent chemoradiotherapy; Adj, adjuvant chemotherapy; IMRT, intensity-modulated radiotherapy 
respectively. The level of significance was set at a $P$ value less than 0.05. Statistical analyses were carried out with the Statistical Package for Social Sciences software (SPSS v16.0; IBM Corporation, Armonk, New York, USA).

\section{Results}

\section{Patient characteristics}

Patient characteristics were detailed in Table 2. The median age at the time of re-irradiation was 49 years old. About $65 \%$ of the patients were rT3-4 disease. Thirty-one patients had synchronous nodal recurrence. Patients were previously treated with two-dimensional conventional radiotherapy (RT) or IMRT to a median dose of 70Gy (range, 36-78.35Gy). Six patients received brachytherapy for local residual disease. Cisplatin-based chemotherapy was given for patients with local and/or regional advanced disease. Forty-four patients received RT alone. The median

Table $\mathbf{2}$ Characteristics of patients with locally recurrent NPC treated with IMRT

\begin{tabular}{|c|c|}
\hline Characteristic & No. (\%) \\
\hline \multicolumn{2}{|l|}{ Gender } \\
\hline Male & 133(72.3) \\
\hline Female & $51(27.7)$ \\
\hline \multicolumn{2}{|c|}{ Age at the time of re-irradiation (years) } \\
\hline Median (range) & $49(23-86)$ \\
\hline \multicolumn{2}{|c|}{ Primary RT technique } \\
\hline 2D-CRT & $103(56)$ \\
\hline IMRT & $43(23.4)$ \\
\hline Unknown & $38(20.7)$ \\
\hline \multicolumn{2}{|l|}{ Primary RT dose (Gy) } \\
\hline Median (range) & $70(60-78.35)$ \\
\hline \multicolumn{2}{|c|}{ Chemotherapy in the first treatment } \\
\hline Yes & $103(56)$ \\
\hline No & $44(23.9)$ \\
\hline Unknown & $37(20.1)$ \\
\hline \multicolumn{2}{|l|}{ rT classification } \\
\hline rT1-2 & $64(34.8)$ \\
\hline rT3-4 & $120(65.2)$ \\
\hline \multicolumn{2}{|c|}{ Presence of synchronous nodal recurrence } \\
\hline No & $153(83.2)$ \\
\hline Yes & $31(16.8)$ \\
\hline \multicolumn{2}{|c|}{ Time interval between initial RT and recurrence (months) } \\
\hline Median (range) & $35(6-388)$ \\
\hline \multicolumn{2}{|l|}{ TTR (years) } \\
\hline$\leq 2$ & $59(32.1)$ \\
\hline$>2$ & $125(67.9)$ \\
\hline
\end{tabular}

Abbreviations: NPC, nasopharyngeal carcinoma; IMRT, intensity-modulated radiotherapy; $R T$, radiotherapy; $2 D-C R T$, two-dimensional conventional radiotherapy; $T R R$, time to recurrence time between initial radiotherapy (RT) and recurrence was 35 months (range 6-388 months).

Local recurrence was diagnosed by biopsy and/or CT/ MRI/PET-CT evidence of progressive skull base erosion and clinical symptoms. One hundred and thirty-six (73.9\%) patients were diagnosed by biopsy. Forty-eight (26.1\%) patients had deep-seated recurrences in the skull base and/or intracranial, and were diagnosed by CT/MRI/PET-CT and clinical symptoms.

All patients completed their planned radiation except for 5 patients who prematurely terminated their treatment because of acute side effects and/or personal reasons after receiving doses between 42-64Gy.

\section{Survival}

The median follow-up time was 32 months (range 3 to 125) for the entire group, and 68 months (range 10 to 125) for the survivors. Eight patients were lost to follow-up. Recurrence was observed in $43(23.4 \%)$ patients. Among them, 27 patients failed in local, 14 patients failed in regional, and 2 patients failed both in local and regional. Sixteen $(8.7 \%)$ patients suffered distant metastasis. Common sites for distant metastasis were lung ( 9 patients), bone ( 5 patients) and liver (4 patients). The 3-year LRFS and DMFS rates were 85.1 and $91.1 \%$, respectively. And the 5-year LRFS and DMFS rates were 71.7 and $85.9 \%$, respectively (Fig. 1).

At the time of analysis, a total of 134 patients $(72.8 \%)$ died. The median survival time was 33 months. The 3 and 5-year OS rates was 46.0 and $28.8 \%$ (Fig. 1). The cause of death was disease progression in 39 patients, radiation-induced injuries in 54 patients (including profuse epistaxis in 44 patients, feeding difficulty in 3 patients and other injuries in 7 patients) and unknown causes in 36 patients. And the remaining 5 patients died of infection or cardio-cerebrovascular disease.

\section{Toxicities}

Late severe adverse effects (SAEs) ( $\geq$ grade 3 toxicities) were recorded after IMRT (Table 3). Common late SAEs included mucosal necrosis, headache, cranial nerve palsy, trismus. Forty-four (24.9\%) patients with mucosal necrosis died of profuse epistaxis since the necrosis involved the internal carotid artery. The median latency for mucosal necrosis was 6.0 months (range 0.5-65.5 months) after re-irradiation.

\section{Prognostic factors}

Univariate and multivariate analysis of potential factors including gender, age, rT stage, fractional dose, chemotherapy, time to recurrence (TTR), IMRT dose, and cumulative dose, brachytherapy for LRFS, DMFS and OS was performed. The results showed that chemotherapy (hazard ratio (HR), 0.210; 95\% confidence interval (CI), 0.065-0.677; $P<0.01$ ) and TTR (HR, 0.291; 95\% CI, 


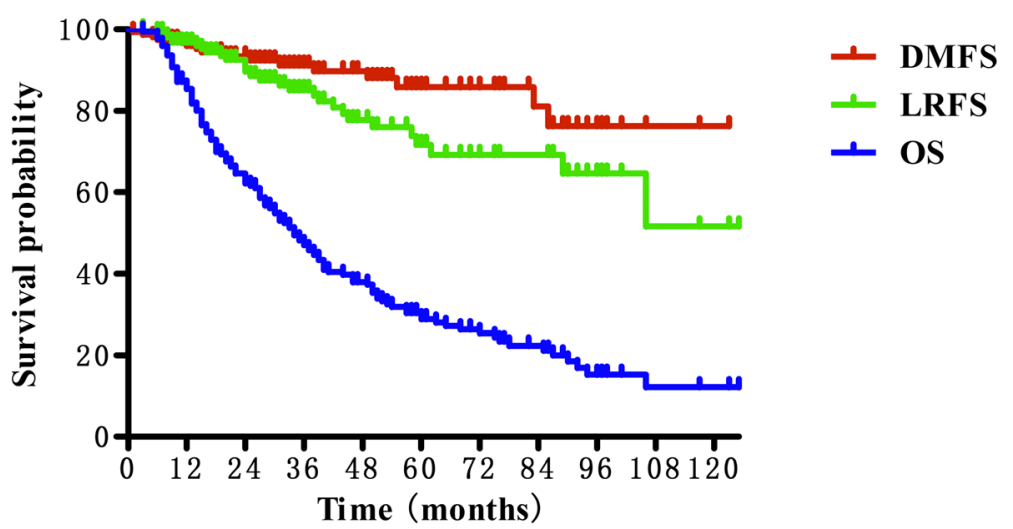

Fig. 1 Kaplan-Meier curves showing local recurrence-free survival (LRFS), distant metastases-free survival (DMFS) and overall survival (OS) for patients with recurrent nasopharyngeal carcinoma

0.089-0.949; $P=0.041$ ) were independent predictors for DMFS. No significant prognostic factors were found for LRFS and OS. The details are shown in Tables 4 and 5.

\section{Discussion}

There is still no consensus on the treatment of locally recurrent NPC. Surgical resection can remove radio-resistant tumor and avoid re-irradiation related injuries for patients with early recurrent disease (rT1-2). It is reported that the 5-year local control (LC) and OS rates for nasopharyngectomy were $43-74 \%$ and $47-62 \%$, respectively [7, 16-19]. However, most of the recurrent tumor was too advanced (rT3-4) at diagnose to be resected [6, 20-22]. For these patients, re-irradiation could be the only potential effective treatment. Re-irradiation with traditional radiation techniques is often associated with severe late complications and resulting in decreased quality of life.

IMRT has been widely used in primary NPC and achieved exciting LC, survival and tolerable toxicities [23-28]. As to recurrent NPC, IMRT may potentially help to improve LC and reduce toxicities. Hsiung et al. [29] compared 3D-CRT and IMRT for the boost or salvage treatment of NPC, and found that IMRT plans can achieve lower normal tissue does and more homogeneous target

Table 3 Late severe toxicities for patients with locally recurrent NPC

\begin{tabular}{lll}
\hline Toxicities & Grade 3-4 & Grade 5 \\
& No. (\%) & No. (\%) \\
\hline Mucosal necrosis & $12(6.8)$ & $44(24.9)$ \\
Headache & $16(12.8)$ & 0 \\
Cranial nerve palsy & $21(11.9)$ & 0 \\
Temporal lobe necrosis & 0 & 0 \\
Trismus & $35(19.9)$ & 0 \\
Hearing deficit & $10(5.6)$ & 0 \\
Neck fibrosis & $1(0.6)$ & 0 \\
\hline
\end{tabular}

Table 4 Univariate analysis of potential prognostic factors

\begin{tabular}{|c|c|c|c|c|c|c|}
\hline \multirow[t]{2}{*}{ Items } & \multicolumn{2}{|c|}{ 3-yr LRFS } & \multicolumn{2}{|c|}{ 3-yr DMFS } & \multicolumn{2}{|c|}{$3-y r$ OS } \\
\hline & $\%$ & $p$ & $\%$ & $p$ & $\%$ & $\mathrm{p}$ \\
\hline \multicolumn{7}{|l|}{ Gender } \\
\hline Male & 90.1 & 0.356 & 89.3 & 0.387 & 41.8 & 0.980 \\
\hline Female & 83.1 & & 91.8 & & 47.6 & \\
\hline \multicolumn{7}{|c|}{ Age (years) } \\
\hline$<60$ & 84.9 & 0.884 & 89.0 & 0.070 & 51.0 & 0.026 \\
\hline$\geq 60$ & 87.2 & & 100 & & 32.4 & \\
\hline \multicolumn{7}{|l|}{ rT stage } \\
\hline rT1-2 & 96.6 & 0.070 & 94.7 & 0.362 & 51.8 & 0.241 \\
\hline rT3-4 & 77.9 & & 88.8 & & 42.9 & \\
\hline \multicolumn{7}{|l|}{ FD (Gy) } \\
\hline$\leq 2$ & 81.6 & 0.298 & 90.3 & 0.820 & 45.5 & 0.645 \\
\hline$>2$ & 94.0 & & 93.2 & & 47.4 & \\
\hline \multicolumn{7}{|c|}{ Use of Chem } \\
\hline No & 88.8 & 0.433 & 83.2 & 0.328 & 49.0 & 0.196 \\
\hline Yes & 83.8 & & 93.9 & & 45.1 & \\
\hline \multicolumn{7}{|l|}{ TTR (years) } \\
\hline$\leq 2$ & 91.7 & 0.248 & 83.9 & 0.035 & 43.6 & 0.977 \\
\hline$>2$ & 82.1 & & 94.8 & & 47.0 & \\
\hline \multicolumn{7}{|c|}{ IMRT dose (Gy) } \\
\hline$<70$ & 85.6 & 0.790 & 93.6 & 0.908 & 42.8 & 0.652 \\
\hline$\geq 70$ & 84.7 & & 86.1 & & 54.0 & \\
\hline \multicolumn{7}{|c|}{ Cumulative dose(Gy) } \\
\hline$<140$ & 85.5 & 0.508 & 88.3 & 0.118 & 49.2 & 0.095 \\
\hline$\geq 140$ & 88.0 & & 96.2 & & 41.0 & \\
\hline \multicolumn{7}{|c|}{ Brachytherapy } \\
\hline No & 79.1 & 0.027 & 90.6 & 0.887 & 44.6 & 0.495 \\
\hline Yes & 100 & & 94.4 & & 57.9 & \\
\hline
\end{tabular}

Abbreviations: LRFS, local recurrence-free survival; DMFS, distant metastasesfree survival; OS, overall survival; $F D$, Fractional dose; Chem, chemotherapy; $\pi R$, time to recurrence 
Table $\mathbf{5}$ Impact of prognostic factors on treatment results by multivariate analysis ( $p$ value)

\begin{tabular}{|c|c|c|c|}
\hline Factors & LRFS & DMFS & OS \\
\hline \multicolumn{4}{|l|}{ Age (years) } \\
\hline$<60$ vs. $\geq 60$ & - & 0.970 & 0.106 \\
\hline \multicolumn{4}{|l|}{ rT stage } \\
\hline rT1-2 vs. rT3-4 & 0.918 & 0.463 & 0.315 \\
\hline \multicolumn{4}{|l|}{ FD (Gy) } \\
\hline$\leq 2$ vs. $>2$ & 0.137 & - & 0.686 \\
\hline \multicolumn{4}{|l|}{ Use of Chem } \\
\hline No vs. Yes & 0.610 & 0.009 & 0.342 \\
\hline \multicolumn{4}{|l|}{ TTR (years) } \\
\hline$\leq 2$ vs. $>2$ & 0.964 & 0.041 & - \\
\hline \multicolumn{4}{|l|}{ IMRT dose (Gy) } \\
\hline$<70$ vs. $\geq 70$ & 0.575 & - & - \\
\hline \multicolumn{4}{|c|}{ Cumulative dose (Gy) } \\
\hline$<140$ vs. $\geq 140$ & - & 0.117 & 0.112 \\
\hline \multicolumn{4}{|l|}{ Brachytherapy } \\
\hline No vs. Yes & 0.051 & - & - \\
\hline
\end{tabular}

Abbreviations: LRFS, local recurrence-free survival; DMFS, distant metastasesfree survival; $O S$, overall survival; $F D$, Fractional dose; Chem, chemotherapy; $T R$, time to recurrence

doses. Several studies have shown satisfactory long-term results of IMRT for recurrent NPC, with a 3-year local control and overall survival rates of $70-89 \%$ and $46-58 \%$, respectively [8-10]. In the present study, we observed a 3-year LRFS and OS of 85.1 and 46.0\%, respectively, which were comparable with other reports. Our results further confirmed that IMRT is an effective choice of treatment for patients with recurrent NPC.

As the local control and survival rates improved, quality of life (QOL) is increasingly emphasized. Radiation-related severe late complications are negative factors affecting QOL. In the study by Hua et al. [8], grade 3-4 late toxicities occurred in $34.4 \%$ of the patients after re-irradiation with IMRT for recurrent NPC. About 30\% of the patients died of excessive nasal bleeding caused by mucosal necrosis. And they also found that the incidence of severe late complications were higher in patients with advanced disease than with early-stage disease. Chan and colleagues [4] recently reported their treatment results of IMRT for recurrent T3-4 NPC in 38 patients. The 3-year local control rate was only $44.3 \%$. What's more, $73.7 \%$ of the patients experienced at least 1 severe late toxicity. Consistent with this, Han et al. [9] reported an incidence of $70.3 \%$ of Grade 3-5 late toxicities after IMRT for recurrent NPC. About 69\% of the patients' deaths were attributed to radiation injuries. In our study, 54 (29.3\%) patients died of radiation-related complications. Among them, 44 patients died of massive hemorrhage, represents the main cause of death. Seventy- five percent (33 out of 44) of these patients were locally advanced disease. All of the above results inform us that radiation induced injuries are still common even in the era of IMRT. We should pay more attention to make balance between the benefits of high-dose IMRT in disease control and the risk of severe late toxicities.

The pathogenesis of radiation-induced normal tissue injury is complex and involves different mechanism including DNA damage repair, inflammation, cell death, angiogenesis, matrix remodeling and so on. Stem cells (SCs) that are defined as the subset of cells with capability to self-renew and to produce more differentiated cells have shown significant implications in radiation-induced late toxicities in recent years [30]. Studies have shown that SCs can be a major target for genetic and epigenetic alteration leading to radiation-induced toxicity $[31,32]$. The ability of resident SCs to reconstitute functional cells determines the onset and severity of the radiation injury [33, 34]. The use of stem cell therapy to promote recovery of normal tissues exposed to radiation is a new but burgeoning area of research [35]. The potential benefits of stem cell therapy include cell replacement, trophic support to the surrounding host tissue, protecting and restoring endogenous cell function and thus reducing normal tissue injury and hasten the recovery of patients [36-39]. Preclinical and early-stage clinical studies have shown encouraging therapeutic potential of stem cells for treating radiation-induced toxicities in different organs [35, 40-42]. However, successful translation to the clinic still faces many barriers including teratoma formation, immunorejection, disease progression, genomic stability and other ethical issues [35].

Mucosal necrosis and massive hemorrhage of the nasopharynx are the most severe late complications and also the leading cause of death after re-irradiation for recurrent NPC. The mechanism of mucosal necrosis is not well clarified. Marx [43] suggested the possible sequence: radiation causes formation of " $3 \mathrm{H}$ "(hypoxic-hypovascular-hypocellular) tissue, in which the ability to replace normal collagen or cellular loss is severely compromised or non existent. This may eventually result in tissue disintegration and chronic unhealed wound. Rupture of radiation-induced internal carotid artery pseudoaneurysm is another cause of massive hemorrhage. The exact mechanism of pseudoneurysm formation is multifactorial. Radiation caused obstruction of vascular, premature atherosclerosis, adventitial fibrosis, and necrosis of the arterial wall. Combined with high blood pressure of the great vessel, it could result in the rupture of the arterial wall and even dissection with extravasation blood [44-47]. Other aggravating factors such as infection, previous surgery, trauma, underlying cardiovascular disease or hypertension can also accelerate the production or the rupture of pseudoaneurysm [46, 48]. Treatment of mucosal necrosis is difficult and there is no effective therapy for it. Hua et al. [49] tried to treat 28 
nasopharyngeal necrosis patients with endoscopy surgery. The results showed that clinical symptoms (foul odor and headache) were relieved to various degrees in all patients and 8 patients were cured after surgery. However,9 (32\%) patients died of sudden nasopharyngeal massive bleeding. Potential negative factors relate to necrosis include old age, co-morbidities such as diabetes, poor general condition and advanced tumor stage [9]. Tian et al. [50] recently found that disease-free interval between primary and re-irradiation (DFI) and recurrent GTV are also independent predictors for mucosal necrosis. Patients with a DFI $\leq 2$ years or GTV $>30 \mathrm{~cm}^{3}$ has higher incidence of mucosal necrosis than those with a DFI $>2$ years or GTV $\leq 30 \mathrm{~cm}^{3}$. More studies focusing on identifying high-risk populations of SAEs and optimal individualized treatment strategies are urgently needed.

The efficacy of chemotherapy for recurrent NPC, either as the sole treatment or combined with RT is still unclear [51]. Results from retrospective studies are less than satisfactory [51-53]. Collectively, the addition of chemotherapy may improve tumor response rate and local control, but no benefit in survival rates. As for locally advanced recurrent NPC, induction chemotherapy can be used to shrink the tumor to permit better target contouring for RT and to better protection for critical normal tissues [54]. In the study by Chua et al. [55] evaluating the effects of induction chemotherapy with cisplatin and gemcitabine before IMRT for locally recurrent NPC, $75 \%$ of the patients had partial response after induction chemotherapy and complete response was achieved in $61 \%$ of the patients after IMRT. The 1-year LRFS and OS rates were 75 and $88 \%$, respectively. Further studies are on the way. In the large series reported by Chang et al. [51], $44.1 \%$ of the patients ( 82 out of 186 recurrent NPC patients) received cisplatin based chemotherapy in addition to RT. However, both univariate and multivariate analysis showed that the addition of chemotherapy did not significantly improve survival $(22.5 \%$ vs. $22.8 \%, p=0.904)$. In our study, chemotherapy was independent predictors for DMFS, but not for LRFS and OS. However, it is worthwhile to note that there was selection bias in our series since chemotherapy was usually given to patients with advanced disease or poor response to RT. Prospective randomized clinical trails are needed to further clarity the role of chemotherapy for recurrent NPC.

\section{Conclusion}

Our long-term results show that re-irradiation with IMRT is an effective choice of treatment for patients with recurrent NPC. Severe late complications are major causes of death, especially for locally advanced disease. Studies focusing on the optimum balance between disease control and quality of life are extremely needed.

\section{Abbreviations}

AJCC/UICC: American Joint Committee on Cancer//Union for International Cancer Control; Cl: Confidence interval; CT: Computed tomography; CTV: Clinical target volume; DFI: Disease-free interval; DMFS: Distant metastases-free survival; ECT: Emission-computed tomography; GTV: Gross tumor volume; IMRT: Intensity modulated radiation therapy; LC: Local control; LRFS: Local recurrence-free survival; MRI: Magnetic resonance imaging; $\mathrm{NCI-CTCAE:} \mathrm{National} \mathrm{Cancer} \mathrm{Institute} \mathrm{Common}$ Toxicity Criteria for Adverse Events; NPC: Nasopharyngeal carcinoma; OAR: Organs at risk; OS: Overall survival; PRV: Planning organ-at-risk volume; PTV: Planning target volume; QOL: Quality of life; RT: Radiotherapy; SAE: Severe adverse effects; SIB: Simultaneous integrated boost; SPSS: Statistical Package for Social Sciences; TPS: Treatment planning system; TTR: Time to recurrence

\section{Acknowledgements}

Not applicable.

\section{Funding}

This research did not receive any specific grant from funding agencies in the public, commercial, or not-for-profit sectors.

\section{Availability of data and materials}

The detailed patients' databases generated and analyzed during this study are not publicly available due to appropriate protection of patients' personal information but are available from the corresponding author on reasonable request.

\section{Authors' contributions}

FFK and JJZ participated in literature research, study design, data collection, data analysis and the draft of the manuscript. CRD managed the patients, carried out the data collection and reviewed the draft. XYH and LK managed the patients and contributed to the data analysis. HMY reviewed the draft, provided comments or revisions, and approved the final manuscript. CSH contributed with study design, critical edit of the manuscript. All authors read and approved the final manuscript.

\section{Ethics approval and consent to participate}

This study was approved by the Institutional Review Boards of Fudan University Shanghai Cancer Center, China. Written informed consent was obtained from the patients before treatment. Due to the retrospective design of the study, the local ethic committee confirmed that informed consent was not necessary from participants.

Consent for publication

Not applicable.

\section{Competing interests}

The authors declare that they have no competing interests.

\section{Publisher's Note}

Springer Nature remains neutral with regard to jurisdictional claims in published maps and institutional affiliations.

\section{Author details}

'Department of Radiation Oncology, Fudan University Shanghai Cancer Center, Shanghai, People's Republic of China. '2Department of Oncology, Shanghai Medical College, Fudan University, Shanghai, People's Republic of China. ${ }^{3}$ Department of Radiation Oncology, Renji Hospital, School of Medicine, Shanghai Jiao Tong University, Shanghai, People's Republic of China. ${ }^{4}$ Department of Radiation Oncology, Shanghai Proton and Heavy lon Center, Fudan University Shanghai Cancer Center, Shanghai, People's Republic of China. 
Received: 4 December 2017 Accepted: 7 November 2018 Published online: 20 November 2018

\section{References}

1. Tuan JK, Ha TC, Ong WS, Siow TR, Tham IW, Yap SP, et al. Late toxicities after conventional radiation therapy alone for nasopharyngeal carcinoma. Radiother Oncol. 2012:104:305-11.

2. Yeh SA, Tang Y, Lui CC, Huang YJ, Huang EY. Treatment outcomes and late complications of 849 patients with nasopharyngeal carcinoma treated with radiotherapy alone. Int J Radiat Oncol Biol Phys. 2005;62:672-9.

3. Lee AW, Poon YF, Foo W, Law SC, Cheung FK, Chan DK, et al. Retrospective analysis of 5037 patients with nasopharyngeal carcinoma treated during 1976-1985: overall survival and patterns of failure. Int J Radiat Oncol Biol Phys. 1992;23:261-70.

4. Chan OSH, Sze HCK, Lee MCH, Chan LLK, Chang ATY, Lee SWM, et al. Reirradiation with intensity-modulated radiotherapy for locally recurrent T3 to T4 nasopharyngeal carcinoma. Head \& neck. 2017;39:533.

5. Chua DT, Wei WI, Sham JS, Hung KN, Au GK. Stereotactic radiosurgery versus gold grain implantation in salvaging local failures of nasopharyngeal carcinoma. Int J Radiat Oncol Biol Phys. 2007;69:469-74.

6. Leung TW, Tung SY, Sze WK, Sze WM, Wong VY, SK O. Salvage brachytherapy for patients with locally persistent nasopharyngeal carcinoma. Int J Radiat Oncol Biol Phys. 2000;47:405-12.

7. Wei WI. Salvage surgery for recurrent primary nasopharyngeal carcinoma. Crit Rev Oncol Hematol. 2000;33:91-8.

8. Hua YJ, Han F, Lu LX, Mai HQ, Guo X, Hong MH, et al. Long-term treatment outcome of recurrent nasopharyngeal carcinoma treated with salvage intensity modulated radiotherapy. Eur J Cancer. 2012;48:3422-8.

9. Han F, Zhao C, Huang SM, Lu LX, Huang Y, Deng XW, et al. Long-term outcomes and prognostic factors of re-irradiation for locally recurrent nasopharyngeal carcinoma using intensity-modulated radiotherapy. Clin Oncol (R Coll Radiol). 2012;24:569-76.

10. Xiao W, Liu S, Tian Y, Guan Y, Huang S, Lin C, et al. Prognostic significance of tumor volume in locally recurrent nasopharyngeal carcinoma treated with salvage intensity-modulated radiotherapy. PLoS One. 2015;10:e0125351.

11. Chen HY, Ma XM, Ye M, Hou YL, Xie HY, Bai YR. Effectiveness and toxicities of intensity-modulated radiotherapy for patients with locally recurrent nasopharyngeal carcinoma. PLoS One. 2013;8:e73918.

12. Chua DT, Sham JS, Leung LH, Au GK. Re-irradiation of nasopharyngeal carcinoma with intensity-modulated radiotherapy. Radiother Oncol. 2005;77:290-4.

13. Tian YM, Guan Y, Xiao WW, Zeng L, Liu S, Lu TX, et al. Long-term survival and late complications in intensity-modulated radiotherapy of locally recurrent T1 to T2 nasopharyngeal carcinoma. Head \& neck. 2016;38:225-31.

14. Lu TX, Mai WY, Teh BS, Zhao C, Han F, Huang Y, et al. Initial experience using intensity-modulated radiotherapy for recurrent nasopharyngeal carcinoma. Int J Radiat Oncol Biol Phys. 2004;58:682-7.

15. Qiu S, Lin S, Tham IW, Pan J, Lu J, Lu JJ. Intensity-modulated radiation therapy in the salvage of locally recurrent nasopharyngeal carcinoma. Int J Radiat Oncol Biol Phys. 2012;83:676-83.

16. Fee WE Jr, Moir MS, Choi EC, Goffinet D. Nasopharyngectomy for recurrent nasopharyngeal cancer: a 2- to 17-year follow-up. Arch Otolaryngol Head Neck Surg. 2002;128:280-4.

17. King WW, Ku PK, Mok CO, Teo PM. Nasopharyngectomy in the treatment of recurrent nasopharyngeal carcinoma: a twelve-year experience. Head \& neck. 2000;22:215-22.

18. Vlantis A, Chan HS, Yu BKH, Tong MCF, Hasselt CAV. Nasopharyngectomy for recurrent NPC: a multivariate analysis. Otolaryngol Head Neck Surg. 2010;143:P67-P8.

19. Chan JY. Surgical management of recurrent nasopharyngeal carcinoma. Oral Oncol. 2014:50:913-7.

20. Li JX, Lu TX, Huang Y, Han F. Clinical characteristics of recurrent nasopharyngeal carcinoma in high-incidence area. TheScientificWorldJOURNAL. 2012;2012:719754.

21. Oksuz DC, Meral G, Uzel O, Cagatay P, Turkan S. Reirradiation for locally recurrent nasopharyngeal carcinoma: treatment results and prognostic factors. Int J Radiat Oncol Biol Phys. 2004;60:388-94.

22. Hwang JM, Fu KK, Phillips TL. Results and prognostic factors in the retreatment of locally recurrent nasopharyngeal carcinoma. Int J Radiat Oncol Biol Phys. 1998;41:1099-111.
23. Hung TM, Chen CC, Lin CY, Ng SH, Kang CJ, Huang SF, et al. Prognostic value of prepontine cistern invasion in nasopharyngeal carcinoma treated by intensity-modulated radiotherapy. Oral Oncol. 2014;50:228-33.

24. Jiang $F$, Jin $T$, Feng $X L$, Jin $Q F$, Chen $X Z$. Long-term outcomes and failure patterns of patients with nasopharyngeal carcinoma staged by magnetic resonance imaging in intensity-modulated radiotherapy era: the Zhejiang Cancer Hospital's experience. J Cancer Res Ther. 2015;11(Suppl 2):C179-84.

25. Wang W, Feng M, Fan Z, Li J, Lang J. Clinical outcomes and prognostic factors of 695 nasopharyngeal carcinoma patients treated with intensitymodulated radiotherapy. Biomed Res Int. 2014;2014:814948.

26. Ou X, Zhou X, Shi Q, Xing X, Yang Y, Xu T, et al. Treatment outcomes and late toxicities of 869 patients with nasopharyngeal carcinoma treated with definitive intensity modulated radiation therapy: new insight into the value of total dose of cisplatin and radiation boost. Oncotarget. 2015;6:38381-97.

27. Sun X, Su S, Chen C, Han F, Zhao C, Xiao W, et al. Long-term outcomes of intensity-modulated radiotherapy for 868 patients with nasopharyngeal carcinoma: an analysis of survival and treatment toxicities. Radiother Oncol. 2014;110:398-403.

28. Wu LR, Liu YT, Jiang N, Fan YX, Wen J, Huang SF, et al. Ten-year survival outcomes for patients with nasopharyngeal carcinoma receiving intensitymodulated radiotherapy: an analysis of 614 patients from a single center. Oral Oncol. 2017:69:26-32.

29. Hsiung CY, Yorke ED, Chui CS, Hunt MA, Ling CC, Huang EY, et al. Intensitymodulated radiotherapy versus conventional three-dimensional conformal radiotherapy for boost or salvage treatment of nasopharyngeal carcinoma. Int J Radiat Oncol Biol Phys. 2002;53:638-47.

30. Hur W, Yoon SK. Molecular pathogenesis of radiation-induced cell toxicity in stem cells. Int J Mol Sci. 2017;18:2749.

31. Mohrin M, Bourke E, Alexander D, Warr MR, Barryholson K, Beau MML, et al. Hematopoietic stem cell quiescence promotes error prone DNA repair and mutagenesis. Cell Stem Cell. 2010;7:174.

32. Beerman I. Accumulation of DNA damage in the aged hematopoietic stem cell compartment. Semin Hematol. 2017;54:12

33. oslash RMB. Preventing or reducing late side effects of radiation therapy: radiobiology meets molecular pathology. Nat Rev Cancer. 2006:6:702-13.

34. Coppes RP, Van dGA, Lombaert IM. Stem cell therapy to reduce radiationinduced normal tissue damage. Semin Radiat Oncol. 2009:19:112.

35. Benderitter M, Caviggioli F, Chapel A, Coppes R, Guha C, Klinger M, et al. Stem cell therapies for the treatment of radiation-induced normal tissue side effects. European Journal on Criminal Policy \& Research. 2013;20:51-72.

36. Lladó J, Haenggeli C, Maragakis NJ, Snyder EY, Rothstein JD. Neural stem cells protect against glutamate-induced excitotoxicity and promote survival of injured motor neurons through the secretion of neurotrophic factors. Mol. Cell. Neurosci. 2004:27:322-31.

37. Ren G, Chen X, Dong F, Li W, Ren X, Zhang Y, et al. Concise review: mesenchymal stem cells and translational medicine: emerging issues. Stem Cells Transl Med. 2012;1:51-8.

38. Teng YD, Benn SC, Kalkanis SN, Shefner JM, Onario RC, Cheng B, et al. Multimodal actions of neural stem cells in a mouse model of ALS: a metaanalysis. Sci Transl Med. 2012:4:165ra4.

39. Tolar J, Blanc KL, Keating A, Blazar BR. Concise review: hitting the right spot with mesenchymal stromal cells. Stem Cells. 2010;28:1446-55.

40. Acharya MM, Christie LA, Lan ML, Donovan PJ, Cotman CW, Fike JR, et al. Rescue of Radiation-Induced Cognitive Impairment through cranial transplantation of human embryonic stem cells. Proc Natl Acad Sci U S A. 2009;106:19150.

41. Benderitter $M$, Gourmelon $\mathrm{P}$, Bey $\mathrm{E}_{\boldsymbol{t}}$ Chapel A, Clairand I, Prat M, et al. New emerging concepts in the medical management of local radiation injury. Health Phys. 2010;98:851

42. Mcquestion M. Evidence-based skin care management in radiation therapy. Semin Oncol Nurs. 2006;22:163-73.

43. Marx RE. Osteoradionecrosis: a new concept of its pathophysiology. J Oral Maxillofac Surg. 1983;41:283-8

44. Cheng KY, Lee KW, Chiang FY, Ho KY, Kuo WR. Rupture of radiation-induced internal carotid artery pseudoaneurysm in a patient with nasopharyngeal carcinoma-spontaneous occlusion of carotid artery due to long-term embolizing performance. Head \& neck. 2008;30:1132-5.

45. Chen HC, Lin CJ, Jen YM, Juan CJ, Hsueh CJ, Lee JC, et al. Ruptured internal carotid pseudoaneurysm in a nasopharyngeal carcinoma patient with skull base osteoradionecrosis. Otolaryngol Head Neck Surg. 2004:130:388-90.

46. Lin FY, Lin JW, Chang H, Yan CL. Pseudoaneurysm of common carotid artery after irradiation: report of a case. Taiwan Yi Xue hui Za Zhi. J Formos Med Assoc. 1988;87:828 
47. Mok JS, Marshall JN, Chan M, van Hasselt CA. Percutaneous embolization to control intractable epistaxis in nasopharyngeal carcinoma. Head \& neck. 1999;21:211.

48. Mak WK, Chow TL, Kwok SP. Radionecrosis of internal carotid artery in nasopharyngeal carcinoma presenting as epistaxis. Aust N Z J Surg. 2000;70:237-8.

49. Hua YJ, Chen MY, Qian CN, Hong MH, Zhao C, Guo L, et al. Postradiation nasopharyngeal necrosis in the patients with nasopharyngeal carcinoma. Head \& neck. 2009;31:807-12.

50. Tian YM, Huang WZ, Yuan X, Bai L, Zhao C, Han F. The challenge in treating locally recurrent T3-4 nasopharyngeal carcinoma: the survival benefit and severe late toxicities of re-irradiation with intensity-modulated radiotherapy. Oncotarget. 2017;8:43450-7.

51. Chang JT, See LC, Liao CT, Ng SH, Wang CH, Chen IH, et al. Locally recurrent nasopharyngeal carcinoma. Radiother Oncol. 2000;54:135-42.

52. Choo R, Tannock I. Chemotherapy for recurrent or metastatic carcinoma of the nasopharynx. A review of the Princess Margaret hospital experience. Cancer. 1991;68:2120-4.

53. Gebbia V, Zerillo G, Restivo G, Speciale R, Cupido G, Lo Bue P, et al. Chemotherapeutic treatment of recurrent and/or metastatic nasopharyngeal carcinoma: a retrospective analysis of 40 cases. $\mathrm{Br}$ J Cancer. 1993:68:191-4.

54. Xu T, Tang J, Gu M, Liu L, Wei W, Yang H. Recurrent nasopharyngea carcinoma: a clinical dilemma and challenge. Curr Oncol. 2013;20:e406-19.

55. Chua DT, Sham JS, Au GK. Induction chemotherapy with cisplatin and gemcitabine followed by reirradiation for locally recurrent nasopharyngeal carcinoma. Am J Clin Oncol. 2005;28:464-71.

Ready to submit your research? Choose BMC and benefit from:

- fast, convenient online submission

- thorough peer review by experienced researchers in your field

- rapid publication on acceptance

- support for research data, including large and complex data types

- gold Open Access which fosters wider collaboration and increased citations

- maximum visibility for your research: over $100 \mathrm{M}$ website views per year

At $\mathrm{BMC}$, research is always in progress.

Learn more biomedcentral.com/submissions 